\title{
Power-oriented and Rapport-oriented Interruptions Among Professional Women in Small Group Conversations
}

\author{
Angelina Subrayan \\ Universiti Teknologi MARA, Malaysia \\ Chittra Muthusamy \\ Universiti Teknologi MARA, Malaysia
}

\begin{abstract}
Interruptions in conversations have long been regarded in negative ways and are associated with dominance and power. The purpose of this study is to examine if women in the professional field interrupt each other in casual conversations with the intention to show power or to show rapport. The samples for this study were the verbal utterances and the interview data from the selected three professional women participants. The utterances among the participants were recorded, transcribed, and analyzed using the Goldberg (1990) model for interruptions. Subsequently, Murata's (1994) and Kennedy and Camden's (1983) sub-categories for interruption analysis were also applied for a detailed analysis. The linguistic elements that existed within the interaction were examined to find out if the speakers demonstrated power-oriented interruptions (intrusive) or rapport-oriented interruptions (cooperative). The study reveals that the function of interruptions in conversations may not be for the purpose of portraying dominance alone. Interruptions among speakers that are supportive and cooperative, promoted solidarity among speakers. This study is significance to understand that with interruptions, speakers can work out a topic or a conversation together to produce a shared meaning. Interruptions could be power-oriented or rapport-oriented, depending on the functions assumed in the context.
\end{abstract}

Index Terms - power-oriented interruption, rapport-oriented interruption, dominance, intrusive, cooperative

\section{INTRODUCTION}

Interruptions in conversations have long been regarded in a negative way and are associated with dominance and power. Research carried out in the past shows that men and women have different communicative competence (Coates \& Pichler, 2011). Interruptions in conversations have the potential to disrupt utterances of the speakers and disorganize the constructions of conversational topics (West \& Zimmerman, 1983). Furthermore, interruptions violate a speaker's right to be engaged in a conversation. Individuals who interrupt repeatedly are usually seen as authoritarian and domineering. However, some studies show that interruptions in a conversation can also act constructively in rescuing and promoting group discussions (Hung, Brooke \& Dunne, 1995). Interruptions can at times be neutral and is not associated with violation of the speakers' right on others (James \& Clarke, 1993).

The basic assumption of a successful communication is assumed that interruptions exhibit disrespect and rudeness for a speaker. It is also believed that interruptions limit the opportunities for the speakers to share ideas as well as sanction interrupters to dominate the topic of conversation and to exercise control over their conversational acquaintance (Greif, 1980; Zimmerman \& West, 1975). What people perceive as an interruption varies systematically across different speakers and speech acts (Shashkevich, 2018). Specifically, interruption acts are deciphered as ways of instituting and upholding a status distinction. According to James and Clarke (1993), a substantial percentage of interruptions in interaction may not be disruptive or dominance related. Interruptions can help speakers to discuss a topic together and create a collective meaning. In other words, interruptions could function as power-oriented (intrusive) or rapportoriented (cooperative), based on the roles of conversations adopted in the context (Dunne \& $\mathrm{Ng}$, 1994). Interruptions may serve to indicate and encourage solidarity between speakers (James \& Clarke 1993). Although there are many articles and books written on interruptions, most of the studies were done on men versus women speakers. Very little research has been done on all women speakers, especially in the Malaysian context. Studies done were mainly on linguistics features that men frequently used in their speech to portray dominant roles. Findings on the use of interruptions by women were overlooked. More new and exhilarating analysis on women's conversation is necessary to understand how interruptions serve various purposes in conversations. There are other eminent details which must be investigated namely, interruptions and their functions in professional women's casual conversations.

Power-oriented interruptions allow a speaker to take over the floor when the first speaker is still speaking or has not completed his or her utterances (James \& Clarke 1993). Women are normally identified with the notion of solidarity and cooperation as they support and strengthen rapport more than men (Tannen, 1992; Coates, 1989; Aries, 1976), and 
their conversations are inclined towards cooperation and substantiating support. Hence, the present study on interruptions in an all-women small group conversation may provide an impetus for avid researchers who strive to examine more on conversational interruptions among professional women in the present era. From this study, other researchers may be able to further understand that the function of interruptions in conversations may not be for the purpose of portraying dominance alone. Interruptions among speakers that are supportive and cooperative, may promote solidarity among speakers.

This study aims to find out if women in the professional field interrupt each other during casual conversations with the intention of indicating power or rapport. During the face-to-face interactions, the participants' non-verbal and verbal communication were observed to discern how and why a particular speaker interrupts another speaker's utterances. The linguistic elements that prevailed within the interactions and manifested power-oriented interruptions (intrusive) or rapport-oriented interruptions (cooperative) were discussed. A small group of professional Malaysian women speakers were chosen for critical analysis on their utterances. Hence, the purpose of this study is to examine how and why interruptions take place among professional women. The study was analyzed using the following research questions:

1.How are interruptions executed linguistically and non-linguistically among the professional women?

2. What are the most frequently exhibited interruptions among the participants?

3.Do the participants' status and position at the workplace influence the way interruptions take place?

4.How does one feel about being interrupted in conversations?

The scope of the study was limited to examining conversations among a small group of professional women speakers from the same workplace. The utterances of the speakers were analyzed using the Goldberg (1990) model for interruptions. Sub-categories for interruption analysis by Murata (1994) and Kennedy \& Camden (1983) were used for detailed analysis. The limited scope allowed analysis of the various types of interruptions that took place among the speakers in the group conversations.

\section{LITERATURE REVIEW}

People are constantly involved in communication with others. The ability to make a communicative process appropriate in a certain context depends on a person's communicative competence (Gravano \& Hirschberg, 2012). People use various communicative strategies for various purposes. Numerous studies on interruptions and gender show significant irregularities between men and women during conversations. As women's participation in the professional fields increases, more demands are made for them to adapt to the linguistic norms of the public domain. It is perceived that their adaptation to a more competitive discourse style ensures success in other problems as well (Michael et al. (2010). Certain speakers can use discursive resources to handle the function of an organization in both the story world and the real world and so do leadership and conversation into being a leader identity (Clifton, 2014). It was found that men interrupt more frequently than women to hold the floor (Zimmerman \& West, 1975; Bohn \& Stutman, 1983; West \& Zimmerman, 1983; Jariah Mohd. Jan, 1999). Interruptions are normally coupled with power and dominance in conversations. Ghafar Samar and Alibakhshi (2007) discovered that the most powerful speaker interrupts and holds the floor more than the other speakers who are less powerful in their study on Iranian men and women. The researchers also discovered that the connection between power and interruption is evidently obvious. Holmes and Stubbe (2003) postulate that one of the different ways of defining power, from a sociological or psychological perspective, is that it is "treated as a relative concept which includes both the ability to control others and the ability to accomplish one's goals"(p.3). This notion is conflicting to the ideas presented by researchers such as Miller (1976) and Rich (1976) where they view the meaning of power as not necessarily entailing domination over others. It is an "autonomous action based on one's beliefs and abilities" (both as cited in Kramarae et al., (1984), p.11). The study, therefore, develops on this concept by differentiating between intentional and unintentional influence. Factors such as authority, manipulation, persuasion and force have become various approaches to accomplishing intentional consequence in conversations.

$\mathrm{Ng}$ and Bradac (1993) have a parallel understanding of the theory of power, distinguishing between two diverse senses of the concept, those of "power to" and "power over." They derived on the work of Russell (1938) in their account of "power to," whereby power is defined as the manufacture of envisioning effects. These effects are then divided into two sub-groups, with the positive effect of "power to" being the recognition of individual or collective goals, and the negative effect that warrant the impediment of other's attainment of goals. "Power over" is defined as the relational facet of power, whereby "one person has power over another person when the two stands in a relationship of dominance and submission (p.3)." There are other studies that show interruptions bring about solidarity and support (Booth-Butterfield \& Booth-Butterfield, 1988; Coates, 1989). James and Clarke (1993) emphasized that not all the interruptions or overlaps are indications of dominance. In fact, interruption can demonstrate the interrupter's supportive approaches rather than disruptive conduct. They deem that “... the extent to which an interruption is interpreted as negative and disruptive is probably not a black and white matter, but rather a matter of degree" (James \& Clarke, 1993, p. 241).

In 1977, Nicola Ferguson established an alternative method for categorizing simultaneous communication. This method involved four categories: simple interruptions, butting-in interruptions, overlaps and silent interruptions. These categories contrasted with a 'perfect speaker switch' - where the first speaker completes his turn, and no simultaneous speech takes place. Ferguson included interruptive behaviour in her typology, that is the 'silent interruptions'. Silent 
interruptions depict occasions when the second speaker begins to talk instantly upon the first speaker's completion of the utterance of a word while in mid turn (James \& Clarke 1993). Subsequently, the first speaker stops talking and gives up the turn. This act is executed so quickly that no simultaneous speech occurs, henceforth the term silent interruption. Cafaro, Glas and Catherine Pelachaud (2016) conducted an experiential study to examine whether various interruption types (i.e. amount of overlap between speakers and utterance completeness) and approaches (disruptive vs. cooperative) in agent mediators in an interaction have any influence on apparent agents' interpersonal manner, commitment and participation. They discovered that the interruption style has an additional impact on the perceived approaches of the agents, while in the use of a cooperative strategy (as contrasting to a disruptive one) an interrupter is observed as being more involved and more immersed in the interaction. To fulfill the literature gap, in this present study, the various types of interruptions were analyzed to find out if a speaker's intention was to demonstrate power or to show rapport.

\section{METHODOLOGY}

This qualitative study approach distinguished between two types of interactional pressures as shown in Goldberg's categorization. The data collection procedure was guided by discourse features characterizing interruptive acts and the participants' responses to the interruptive acts. The participants' responses were analyzed based on context and the interpretive context. The theoretical framework focused on Goldberg's (1990) divided interruptions along the powerrapport continuum and provided a means for assessing the meaning of each interruption.

TABLE 1

CLASSIFICATIONS OF INTERRUPTIONS ACCORDING TO GOLDBERG (1990)

\begin{tabular}{|c|c|c|}
\hline i. & Power-oriented interruptions & $\begin{array}{c}\text { They are broadly heard as impolite, intrusive, and inappropriate, revealing the } \\
\text { interrupter's aggression, dislike or apathy towards the interrupted speaker or the talk } \\
\text { at hand. }\end{array}$ \\
\hline ii. & Rapport-oriented interruptions & They are generally inferred as interpretation of empathy, solidarity, or interest. \\
\hline
\end{tabular}

TABLE 2

SUB-CATEGORIES OF POWER-ORIENTED AND RAPPORT-ORIENTED INTERRUPTIONS

\begin{tabular}{|l|r|}
\hline Power-oriented interruptions & Murata's (1994) \\
\hline \multirow{2}{*}{ Rapport oriented interruptions } & Disagreement, \\
\cline { 2 - 2 } & Floor taking \\
\cline { 2 - 2 } & Topic change. \\
\hline & Kennedy \& Camden (1983) \\
\cline { 2 - 2 } & Assistance \\
\cline { 2 - 2 } & Agreement \\
\hline
\end{tabular}

\section{A. Sampling}

The participants consisted of a group of three professional women who met regularly for meetings and they usually continued with casual conversations. The all women participants were staff members of a public university. The duration for each conversation was not specified during the recording sessions, but they were reminded to speak enough to engage in a discussion. The selection criteria were based on purposeful sampling and their presence on the campus was reliable as they were involved in committee meetings throughout the period the study was carried out. The participants' status and position at the workplace were also considered before they were selected. The status and the position they held at the workplace mattered as the study involved finding out if these criteria influenced the interruptions during conversations. Roger (1988) observed that interactions between strangers are prone to result in constraints enforced by 'social norms' and so do not reflect natural interaction behaviour. Therefore, on the strength of this observation, all participants forming the group knew each other well. Table 3 below provides details of the participants.

TABLE 3

DETAILS OF PARTICIPANTS

\begin{tabular}{|c|c|c|c|}
\hline \multicolumn{3}{|c|}{ DETAILS OF PARTICIPANTS } & Profession \\
\hline Participants & Age & Qualification & Associate Professor \\
\hline F1 & 54 & Phd & Senior Lecturer \\
\hline F3 & 42 & Masters & Lecturer \\
\hline
\end{tabular}

The participants from the small group of professional women were colleagues who have been working in the language department of the university faculty. The 3 participants voluntarily accepted the request to be the participants in the conversations. For the purpose of analysis, the participants are referred to as female 1(F1), female 2(F2) and female 3(F3). F1 and F2 have known each other for 3 years. F3 was a new staff member who has been in the campus for two years. She previously worked in another campus for three years and therefore has some working experience. The three participants have been meeting regularly for committee meetings. They usually engaged in casual conversations after the committee meetings. 


\section{B. Data Collection Method}

The conversations among the participants were recorded with a Compact Disk (CD) recorder. The participants' nonverbal communications were observed, and observation notes were taken for additional information. The data for the study consists of the spoken interactions among the three participants stated in Table 3. The best method of data collection was by a CD recorder to transcribe those instances of interaction, sanctioning the ease of analysis later. During the first recording sessions, the participants were uncomfortable with the researchers sitting through their meetings and therefore for subsequent recordings, the researchers decided to observe the participants a little distance away from the scenarios to allow natural conversations to take place.

TABLE 4

CONVERSATION SESSIONS

\begin{tabular}{|c|c|c|c|}
\hline Sessions & Date & Venue & Duration \\
\hline 1 & 4 Nov 2019 & Staff lounge & 20 minutes \\
\hline 2 & 7 Nov 2019 & Faculty office & 15 minutes \\
\hline 3 & 11 Nov 2019 & Pantry & 18 minutes \\
\hline 4 & 20 Nov 2019 lounge & 10 minutes \\
\hline 5 & 4 Dec 2019 & Resource room & 15 minutes \\
\hline 6 & 6 Dec 2019 & Staff lounge & 22 minutes \\
\hline
\end{tabular}

The data for the study are the utterances of the participants in the all-women casual conversations at a workplace. The topics of their conversations were spontaneous. For triangulation and thick description, an interview session with the 3 participants was conducted on the 30th of December, 2019, to get their feedback on the effects of interruptions on them.

\section{Data Analysis Method}

The study analyzed using the qualitative approach to explore the phenomena of power-related and non-power related interruptions in the participants' conversation. The utterances in the conversations and the speakers' non-verbal communication were used as the research data to analyze and to find out if they function to show intrusiveness or solidarity. Certain speech acts like turn-taking, intonations and reactions from the speakers were observed to supplement the analysis on the functions of interruptions. The 3 participants were interviewed at different times and locations on the same day to get information about their feelings and opinions about interruptions in their conversations. The interview questions were semi-structured.

\section{Ethical Considerations}

Since the data for the study was taken from the utterances during a group conversation, verbal permission was obtained from the participants. However, for the sake of privacy the participants requested that their names be withheld in the transcriptions. It is important to note the ethical issue involving participants by addressing their anonymity (Sebba, 2007). Since the participants have the tendency to mention names in their conversations, the use of pseudonyms to replace their names was allowed by the participants. The researchers were also reminded to keep the name of the institution where the data was taken from, confidential.

\section{FINDINGS AND DiSCUSSION}

The analysis and discussions were based on the utterances of the participants during the casual conversations. The power-oriented and rapport-oriented interruptions were examined by following the order of the theoretical subcategories' framework. The analysis of the utterances was linked to the three participants' status and position at the workplace. The findings show how factors like relationships are important elements that influenced the utterances of the women. The analysis on interruptions among the professional women in the small group conversation was guided by the research questions. Intrusive interruptions create threats to the speaker's sphere by unsettling the process and/or content of the continuing conversation (Goldberg, 1990). The Linguistic and non-Linguistic execution of interruptions among professional women or power-oriented interruptions are shown below.

\section{A. Power-orientated Interruptions}

\section{Disagreement}

Disagreement interruption emerges when the interlocutor in the position of the listener conflicts with what is being said by the existing speaker and wishes to voice her opinion immediately. 


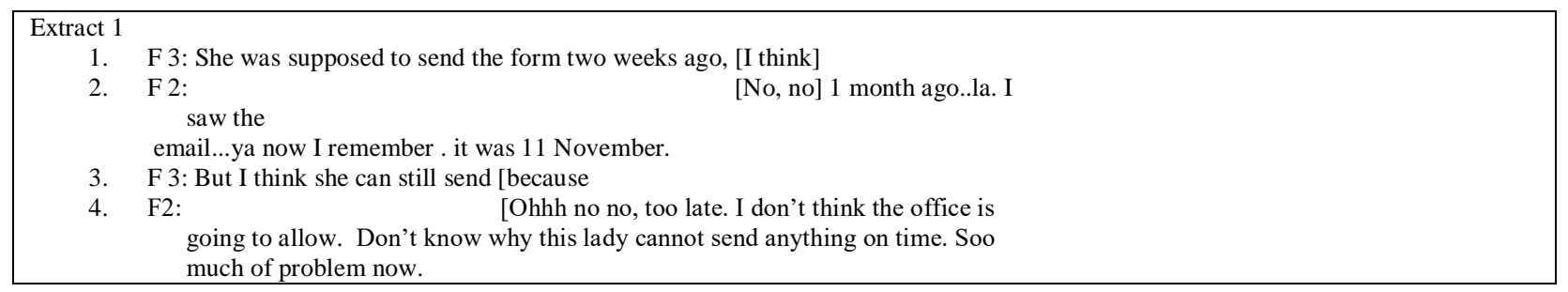

\section{Analysis for Extract 1}

F2 interrupted F3 in the middle of the sentence and did not allow her to complete her utterance. F2 interrupted F3 again without allowing her to complete her explanation. F2 disrupted the flow of the conversation by controlling the topic. She interrupted by disagreeing as soon as important details were given by F3. The non-linguistic aspect of the conversation which was F2's high-pitched voice helped her to gain control and dominate the conversation.

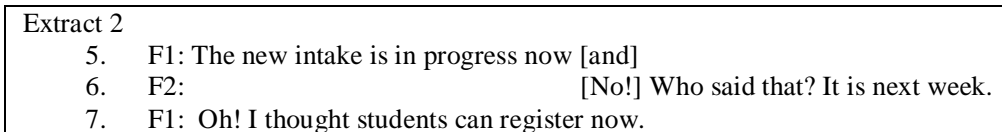

\section{Analysis for Extract 2}

F2 interrupted F1 again without allowing F1 to complete her sentences. F2 did not argue with F1 but submitted and accepted F2's disagreement without interrupting her.

\section{Floor taking}

In floor taking, the interrupter does not intend to change the topic of the current speaker. In its place, the interrupter frequently advanced on the topic of the current speaker and does so by taking over the floor from the current speaker.

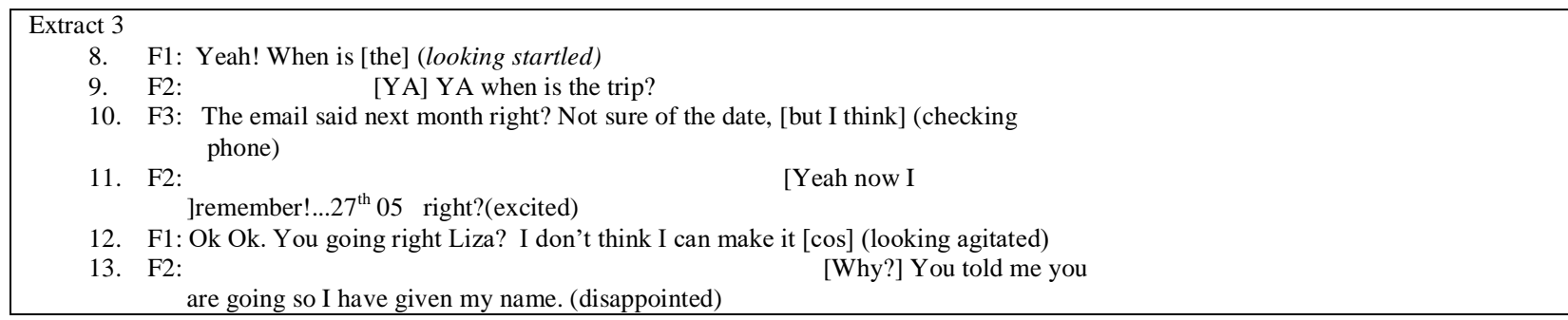

\section{Analysis for extract 3}

When F1 started to ask a question, F2 interrupted without allowing F1 to complete her question. F2 continued her utterances by staying on the same topic by repeating the same question that F1 wanted to ask without any interruption. F2 successfully completed her utterances without intrusion from F1 and F3. F2 also interrupted F3 and continued the discussion on the same topic about the trip. F2 interrupted F1 again without letting her complete her sentence.

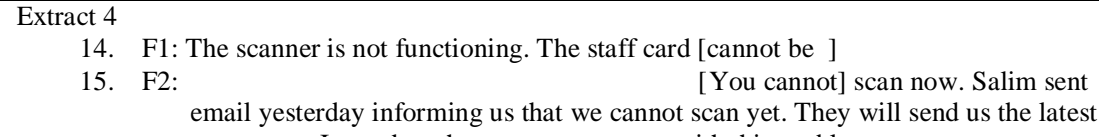

Analysis for Extract 4

F1 initiated a conversation and before she could complete her utterances F2 managed to interrupt her. F2 developed the topic of the current speaker and did so by taking over the floor from the current speaker. She stayed on the same topic, but exercised her power to dominate the conversation from F1. Observation from F1's facial expression during this session revealed that she did not look too pleased.

3. Topic change

Here in the conversational act, the interrupter is to some degree more aggressive than in the floor-taking position since she must accomplish the task of changing the topic.

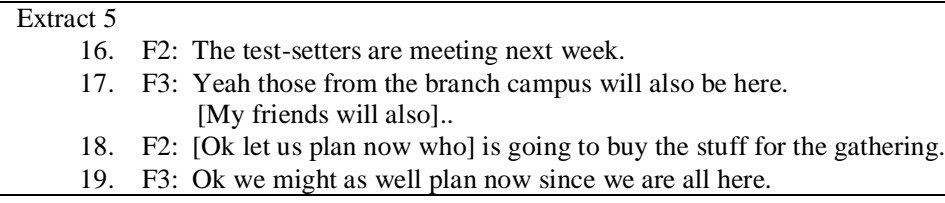


F2 interrupted F3 again by taking over the floor and changing the topic of conversation. F2 interrupted more aggressively this time when she interrupted F3 without paying attention to what she was saying. F3 was more authoritative and forceful here. From the observation, F2 used the conversation as a contest as well as to be more competitive. F3's facial expression revealed disappointment when she was interrupted by F2. F3's response to F2 was more cooperative but her body language showed restlessness.

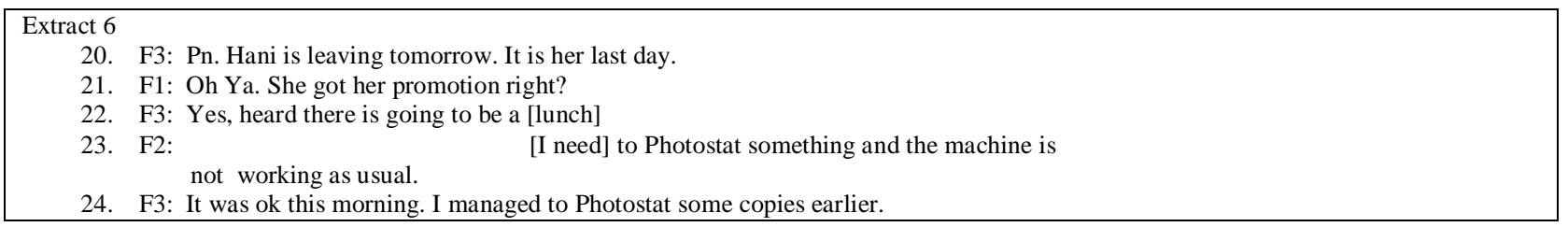

\section{Analysis for Extract 6}

In Extract 6, F1 and F3 were discussing about a staff's promotion. F2 managed to interrupt and change the topic of conversation about a staff's promotion to a topic about the Photostat machine which was not functioning. F3 did not return to her previous topic after she was interrupted by F2. The floor was taken over by F2 and she projected her dominant attitude by performing conversational strategies that occupied the position of authority in the conversation.

\section{B. Rapport-oriented Interruptions}

Rapport-oriented interruptions are expressions of empathy, solidarity, or interest. Murata (1994), states that cooperative interruptions are expected to assist the speaker by coordinating on the process and content of the progressing conversation. The cooperative category utilized in the current research involved three subcategories: assistance, agreement, and clarification. Agreement and clarification were acquired from Kennedy and Camden (1983), whereas assistance was developed based on Li's (2001) study.

\section{Assistance}

This happens when the interrupter identifies that the speaker requires assistance. The interrupter provides the current speaker with a word, phrase, sentence, or idea.

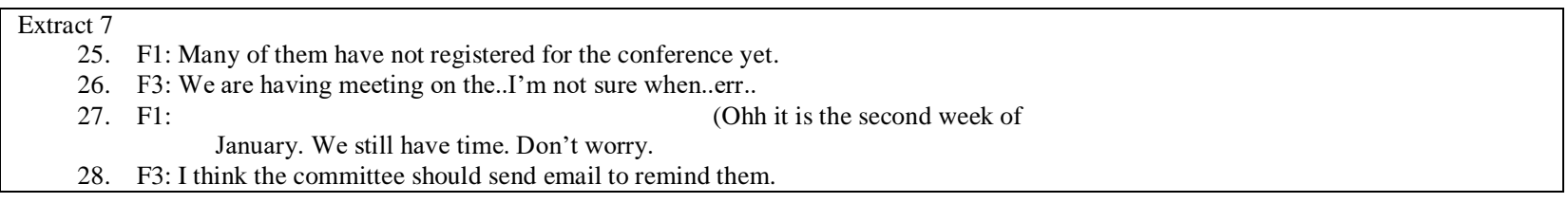

\section{Analysis}

F1 allowed F3 to speak without interrupting her. F1 only interrupted F3 when she perceived that F3 needed help because she could not remember the date of an event. F1 allowed F3 to continue which the same topic. F1 showed rapport-oriented interruptions when she provided F3 with the answer she needed. The collaborative style assumed F1 and F3 were working together and helping each other during the conversation.

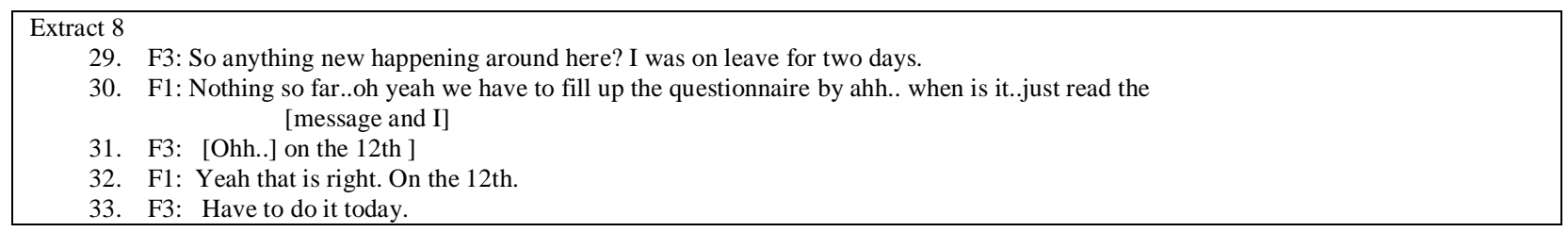

\section{Analysis for Extract 8}

F3 interrupted F1 because F1 needed assistance to get the date to fill in the questionnaire. While F1 was struggling to remember the date, F3 showed rapport by assisting her with the correct answer. F3 was being supportive when she showed involvement and camaraderie.

\section{Agreement}

Based on a study by Kennedy and Camden (1983), an agreement interruption allowed the interrupter to display concurrence, compliance, understanding, or support. At times, the interruption also presents as an extension or elaboration of the idea being bestowed by the speaker.

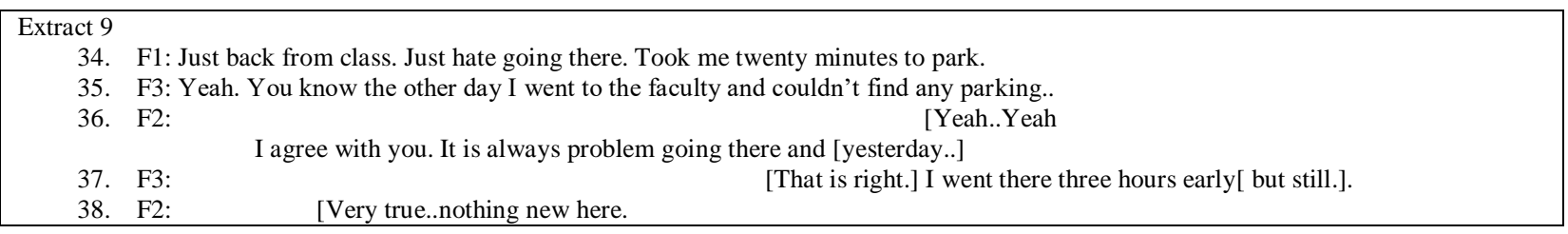


Analysis

F3 initiated a conversation with F2. F2 interrupted to agree with F3. F2 interrupted F3 to signal a certain level of engagement with F3. This indicates that F2 was paying attention to F3 and was interested in hearing more news. There was active participation by both the participants. F2 nodded and showed rapport by reflecting enthusiasm.

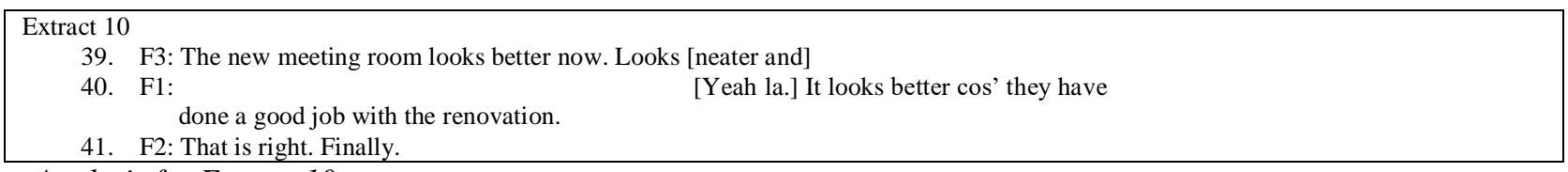

Analysis for Extract 10

F1 interrupted F3 before she completed her utterances. F1 projected agreement and her facial expression showed that she was smiling. F2 and F3 were paying attention to each other and showed rapport in their conversation.

\section{Clarification}

This kind of interruption is normally initiated by the listener, to understand the message that is sent by the speaker (Kennedy \& Camden, 1983). The fundamental intention of the interruption is to have the current speaker clarify or reveal a previously elicited piece of information that the listener is uncertain of.

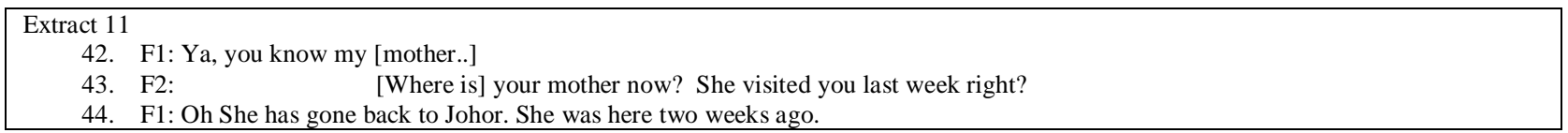

\section{Analysis for Extract 11}

F1 began talking about herself and F2 interrupted F1 to get information about her mother. F1 responded and continued with the topic about her mother. F2 showed solidarity when she supported F1by showing interest in F1's mother.

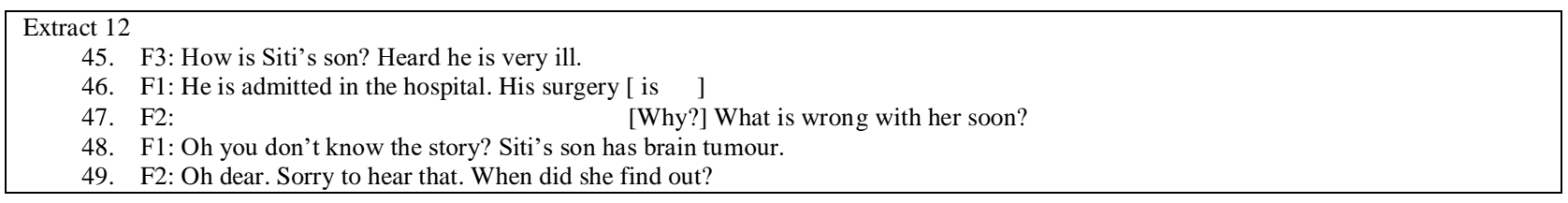

\section{Analysis for Extract 12}

The function of interruption here was to show rapport. F2 interrupted F1 because she wanted to know what was wrong with her colleague's son. F1 showed cooperativeness in this conversation by replying patiently to F2's question.

There were three speakers involved in extract 3 but F2 had the most number of turns. It is apparent from the extracts that F2 interrupted more frequently than the other two speakers. In producing this description, the most salient characteristic in the conversation is, although F2 interrupted frequently, she still stayed on the same topic most of the time. However, by not allowing the other speakers to complete their utterances, F2 took the floor and was in control. F2 portrayed control of power by violating the turn-taking strategies that governed the discussions. F2 dominated the conversations that were aggravated by the interruptive nature of turn-taking.

The non-linguistic aspect of the conversation based on observation, supports the notion that F2 was in control of the conversations. This was identified through the non-linguistic behaviour of F3 when she was not much involved in the conversations throughout the 6 sessions. She avoided the conversation a few minutes during the sessions. In addition, F1 was not pleased with the frequent interruptions by F2 as seen from her facial expressions. F1 looked startled as soon as F2 interrupted her the first time. F1 appeared dismayed several times when interrupted by F2 especially when she attempted to take over the floor and succeeded to dominate the conversation. F2's tendency to interrupt frequently was considered impolite, intrusive and conveyed her aggressive conduct. Although F1 was holding higher status and position at the work place, she did not reprimand F2 for interrupting her utterances.

All three participants exhibited a certain number of interruptions during the whole period of the six conversations. F1's interruptions were more towards rapport oriented as her interruptions were to show agreement. F2's interruptions were more power oriented as she interrupted more to disagree with the other participants' views. Among the three participants, F2 changed the topic more than the others. F3 displayed more rapport-oriented interruptions as she was inclined to agree more with the participants' utterances. Interruptions can be disruptive when it was used to control the conversation by taking over the floor and, they can be supportive when it shows involvement and solidarity. Rapportoriented interruptions are perceived as acts of collaboration in that they strengthen and add to the progress of the conversation by contributing the participants with immediate response, filling in informational inconsistency, developing on the participants' topic or theme, including evaluative comments, or requesting the speaker to supply more remarks. Besides, rapport-oriented interruptions permit one to linger on-topic.

\section{The Most Frequently Exhibited Interruptions among the Participants}


TABLE 5

FREQUENCY COUNTS OF THE SIX TYPES OF INTERRUPTIONS

\begin{tabular}{|l|l|l|l|}
\hline $\begin{array}{l}\text { Subcategories of } \\
\text { interruptions }\end{array}$ & F1 & F2 & F3 \\
\hline Power Oriented & & & \\
\hline Disagreement & 2 & $\mathbf{1 0}$ & 3 \\
\hline Floor taking & 2 & $\mathbf{8}$ & 2 \\
\hline Topic change & 1 & $\mathbf{4}$ & 2 \\
\hline Rapport oriented & & & 8 \\
\hline Assistance & 6 & 4 & 10 \\
\hline Agreement & 9 & 3 & 9 \\
\hline Clarification & 7 & 4 & \\
\hline
\end{tabular}

Analysis

The three participants exhibited a different number of interruptions during the period of the study. The six conversation sessions took place at different intervals and various settings at the workplace within the period of one month. F1's interruptions were more towards rapport oriented as her interruptions were to show agreement. F2's interruptions were more power-oriented as she interrupted more to disagree with the other participants' view. She also took over the floor 8 times. Among the 3 participants, F2 changed the topic of conversation more than the others. F3 displayed more rapport-oriented interruptions as she agreed more with the other 2 participants' discussions.

\section{The Influence of the Participants' Status and Position in Power-oriented Interruptions}

The frequencies of power-oriented interruptions and rapport-oriented interruptions are summed across the status and position of the participants at the workplace. The results in Table 5 show that F2 interrupted more frequently compared to the other two participants. F2's workplace status was lower than F1, but she interrupted more frequently during the duration of the six conversations. Thus, the data illustrates that status and position of a person do not contribute to power among the speakers. Interruptions do not necessarily have to be synonymous with power. Although certain interruptions may portray power, others may signal rapport and cooperativeness.

In this study, it is assumed that the social practices by the speakers also contributed to the nature of interruptions. Higher status in the workplace did not contribute to power-oriented interruptions. However, more knowledge and access to certain practices at the workplace placed the participants in positions of greater power. Power is not 'held' by individuals through social status and position at workplace but rather developed through interaction in an array of relationships.

\section{E. Participants' Views on Interruptions in Casual Conversations}

All three participants were interviewed on 30 December 2019 at different intervals. The following questions were asked during the interview sessions which lasted for about 10 minutes per participant. The extracts from their responses are given below. The interview questions were semi-structured.

Interview questions for F1

Was your conversation interrupted by any of the two participants who were involved in study?

"Yeah I realized that F2 has the habit of interrupting when others are speaking. She did annoy me a few times but I realized that it is her habit. She does that with everyone. I noticed that. F3 is a little quiet so she is ok."

As a senior staff in this campus, how do you feel when interrupted by F2?

"I don't mind if she interrupts me to show support or to clarify something. But sometimes she takes over the topic. That I think is rude. However, since it is a casual conversation, I did not take it seriously. Well, she is also cooperative at times you know."

Interview questions for F2How do you regard interruptions in conversations?

"I believe interruption is rude and people should always listen carefully to what one is saying without interrupting them."

Do you realize that you have interrupted your colleagues on a several occasions during the whole course of the conversations?

"Did I? Ehh...close friends of mine have complaint to me that I have this habit of interrupting when others are still speaking. I know it can be rude at times but I just want to show them how excited I am in a conversation. Sometimes I realize that I don't wait for them. It is hard for me because...eh because...Y You see.. I have been doing that for a long time. I hope they realize that I interrupted because I want to know what is going on."

Questions for F3

Did any of the two participants interrupt your speech during the recording sessions?

Yes, F2 interrupted me quite a number of times..ehh but I don't think she was aware of what she was doing...

Do you think one's status and position at a workplace influence one's habit of interrupting others? 


"No, no I strongly disagree. I know F1 is higher status and she is an associate professor. I have high respect for her. F2' s intention to
interrupt is not to show dominance or to control her. However, I do have certain amount of respect for people who are higher rank than me.
So I am very careful in this matter.

\section{How do you feel about being interrupted in a conversation?}

"I just hope she stops being intrusive. She should let others complete their turn before she speaks. Sometimes it can be annoying. But I realize, she doesn't interrupt much during our formal meetings. Maybe she is afraid of the dean.(laughing)'

\section{F. Analysis of the Responses from the Interview Questions}

The interview questions provided the opinion and feedback from the three participants. All three participants have agreed that interruptions in conversations display rudeness. Rapport-oriented interruption for the purpose of showing cooperativeness is acceptable by the participants. One of the participants agreed that a person's status and position do not determine the frequency of interruptions in a conversation. F1 and F3 believed that F2's reason for interrupting frequently is a frequent habit that she needed to address. They were annoyed several times, but they also got used to her tendency to interrupt. They mentioned that they were too polite to inform her because on most instances she also showed cooperativeness.

\section{CONCLUSION}

Power and dominance are not always associated with men alone. Women can also display power as seen from this small study. Interruptions in conversations are not for the purpose of portraying dominance alone. Interruptions do not need to be synonymous with power. The study has attempted to differentiate between power and rapport-oriented interruptions. It has provided a mode for assessing the meaning of the six different interruptions as a display of relational power or rapport. Future research on interruptions among women speakers from a different culture and setting is necessary for a more in-depth study.

\section{REFERENCES}

[1] Aries, E. (1976). Interaction Patterns and Themes of Male, Female, and Mixed Groups. Small Group Behaviour 7, 7-18

[2] Booth-Butterfield, S. (1988). Inhibition and student recall of instructional messages. Communication Education 37- 312-324.

[3] Bohn, E., \& Stutman, R. (1983). Sex role differences in the relational control dimension of dyadic interaction. Women's Studies in Communication 6, 965-104.

[4] Cafaro, A., Glas, G. \& Pelachaud, C. (2016). The Effects of Interrupting Behavior on Interpersonal Attitude and Engagement in Dyadic Interactions, 15th International Conference on Autonomous Agents and Multiagent Systems AAMAS'16, Singapore, May 2016.

[5] Clifton, J. (2014). Small stories, positioning, and the discursive construction of leader identity in business meetings. Leadership, 10, 99-117. doi:10.1177/1742715013504428 Google Scholar, SAGE Journals, ISI.

[6] Coates, J., \& Pichler, P. (2011). Language and gender: A reader. Chichester, West Sussex, U.K: Wiley-Blackwell.

[7] Coates, J. (1989). Gossip revisited: Language in all-female group. In J. Coates \& D. Cameron (Eds.), Women in their speech community (94-122). New York: Longman.

[8] Dunne, M., \& Ng, S. H. (1994). Simultaneous speech in small group conversation: All-together-now and one-at-a-time? Journal of Language and Social Psychology 13, 45-71.

[9] Ferguson, N. (1977). Simultaneous speech, interruptions, and dominance. British Journal of Social and Clinical Psychology Banner. 16(4), 295-302.

[10] Ghafar Samar, R. \& Alibakhshi, G. (2007). The Gender Linked Differences in the Use of Linguistic Strategies in Face-to Face Communication. The Linguistics Journal 3 (3), 59-71.

[11] Goldberg, J (1990) 'Interrupting the Discourse on Interruptions'. Journal of Pragmatics, 14: 883- 904

[12] Gravano, A. \& Hirschberg, J. (2012). A corpus-based study of interruptions in spoken dialogue. In INTERSPEECH, 13th Annual Conference of the International Speech Communication Association. 855-858.

[13] Greif, E. B. (1980). Sex differences in parent-child conversations. Women's Studies International Quarterly 3,255258.

[14] Holmes, J. \& Stubbe, M. (2003). Power and Politeness in the Workplace: A Sociolinguistic Analysis of Talk at Work. London: Longman.

[15] Hung Ng, S., Brooke, M., \& Dunne, M. (1995). Interruption and influence in discussion groups. Journal of Language and Social Psychology 14(4), 369-381.

[16] James, D., \& Clarke, S. (1993). Women, men, and interruptions: A critical review. In D. Tannen (Ed.), Oxford studies in sociolinguistics. Gender and conversational interaction (pp. 231-280). New York, NY, US: Oxford University Press.

[17] Jariah Mohd. Jan. (1999). Malaysian Talk Show: A Study of Power and Solidarity in Inter- Gender Verbal Interaction (Unpublished Ph. D Thesis). University of Malaya, Kuala Lumpur, Malaysia.

[18] Kennedy, C. W., \& Camden, C. T. (1983). A new look at interruption. Western Journal of Speech Communication 47, 45-58.

[19] Kramarae, C, Muriel S \& William M. O Barr (eds). (1984). Language and Power. Beverly Hills, CA: Sage.

[20] Michael, A.S., Liaw, S. C., Muthusamy, C., \& Veeravagu, J. (2010). Gendered-Linked Differences in Speech Styles: Analysing Linguistic and Gender in the Malaysian Context. Cross Cultural Communication, 6 (1) 18-28 http://www.cscanada.net/index.php/ccc/issue/view/60 (accessed 21/01/2021).

[21] Murata, K. (1994). Intrusive or cooperative? A cross-cultural study of interruption. Journal of Pragmatics 21, 385-400.

[22] Ng, S. H., \& Bradac, J. J. (1993). Language and language behaviors, Vol. 3. Power in language: Verbal communication and 
social influence. Thousand Oaks, CA, US: Sage Publications, Inc.

[23] Roger, D., Bull, P. \& Smith, S. (1988). The development of a comprehensive system for classifying interruptions. Journal of Language and Social Psychology 7(1), 27-34.

[24] Sebba, M. (2007). Spelling and Society. Cambridge: Cambridge University Press.

[25] Shashkevich, A. (2018). Stanford researcher examines how people perceive interruptions in conversation. https://news.stanford.edu/2018/05/02/exploring-interruption-conversation/ (accessed 21/01/2021).

[26] Tannen, D. (1992). That's Not What I Meant! How Conversational Style Makes or Breaks Your Relations with Others. London: Virago Press.

[27] West, C. and Zimmerman, D. (1987). Doing Gender. Gender \& Society 1 (2), 125-151.

[28] Zimmerman, D. H., \& West, C. (1975). Sex roles, interruptions, and silences in conversation. In B. Thome \& N. Henley (Eds.), Language and sex: Difference and dominance (105-126). Rowley, MA: Newbury House.

Angelina Subrayan is a senior lecturer at a public university. She has more than thirty years of teaching experience and has published numerous articles with several reputable journals. Her areas of expertise include Language and Linguistics, Language and Professional Communication and Literature studies that include Victorian and early twentieth century writings.

Chittra Muthusamy is currently a senior lecturer with Akademi Pengajian Bahasa, Universiti Teknologi Mara. Her areas of academic interests are Language, Literature and Methodology in Teaching Literature in the ESL Classroom. 